\title{
Formulaic Sequences and Their Relationship with Speaking and Listening Abilities
}

\author{
Ebrahim Khodadady (Corresponding author) \\ Department of English Language and Literature, Ferdowsi University of Mashhad \\ Mashhad, 91779-48883, Iran \\ E-mail: ekhodadady@ferdowsi.um.ac.ir
}

Saeedeh Shamsaee

Department of English Language and Literature, Ferdowsi University of Mashhad

Mashhad, 91779-48883, Iran

E-mail: saeedeh.shamsaee@stu-mail.um.ac.ir

Received: July 25, 2011

doi:10.5539/elt.v5n2p39
Accepted: August 24, 2011

Published: February 1, 2012

\begin{abstract}
This paper aims to investigate the relationship between the use of formulaic sequences (FSs), speaking ability and speech fluency. Formulae form a considerable portion of native-speakers' speech and mastering them helps learners to appear more native-like. In this study 41 learners of English were interviewed and their speech fluency, level of proficiency and also the frequency of their use of FSs were measured and statistically analyzed. The results of frequency and correlation analyses show that among the seven categories of FSs proposed by Ohlrogge (2009), Personal Stance Markers and Transitions show significant correlation with speaking scores. In addition, discriminant function analysis shows that the frequency of the use of these two categories of FSs can predict the learners' overall speaking scores better then their speech fluency. The applications and implications of the findings for language teaching and phraseology are discussed.
\end{abstract}

Keywords: Formulaic sequences, Collocations, Speech fluency, Listening proficiency, Discriminant Function Analysis

\section{Introduction}

Speech fluency is hard to acquire for most language learners but greatly contributes to one's image of successful and fluent speaking. Identifying and analyzing working mechanisms that influence fluency then should be regarded significant for our understanding of the complexities of speaking. It is probably one of the most important qualities of speech which greatly contributes to examiners' intuitive understanding of proficiency and technical assessment of learners' oral performance. Since Wood (2008) claimed formulaic sequences (FSs) make meaningful contribution to language learners' speech fluency, this study was designed to test the claim and explore the role of FSs in its development. More specifically, the study addresses the following research questions:

1. Which types of FSs are used by language learners more frequently?

2. Is there any significant relationship between the frequency of the use of FSs by language learners and their level of listening and speaking ability?

3. How does the frequency of the use of FSs predict learner' speech fluency?

\section{Literature Review}

In this section, definition and significance of FSs and their place in language learning are discussed. In addition, different perspectives to the dynamics of linguistic fluency and approaches for studying the FSs are mentioned. Finally some of the previous empirical studies conducted on the relationship between speech fluency and the use of FSs are reviewed and one of the various frameworks offered for the identification of FSs is adopted from the available literature to explore the research questions raised in the study.

\subsection{Definition of Formulaic Sequence}

FSs are named differently and defined in various ways in the literature. On discourse level, for example, speakers 
resort to sequencing words and consequently to sequencing of sentences to express themselves. This process of word sequencing and stringing them into sentences help listeners keep them in mind as a whole rather than as a combination of individual elements. Bannard and Lieven (2009) defined FSs as multiword pieces of language that occurs a lot. Two distinctive features of FSs differentiating them from ordinary sentences are their restricted form and restricted distribution (Corrigan, Moravcisk, Ouali, \& Wheatley, 2009). The first feature highlights the fact that formulae are limited in their set to fill structural slots. In fact, FSs act like words in spite of their surface forms which look like sentences. Idioms can, for example, be categorized as one of the subclasses of FSs because of their rigidity of forms and their non-compositionality. Additionally, it should be pointed out that formulaic constructions have semantic and syntactic integrity maintained through restricted choice of certain words. The arrangement and selection of these linguistic units is narrow and therefore, in constructing sentences and phrases, the range of allowable and possible options become more and more limited.

As the second distinctive feature of FSs, restricted distribution limits their occurrence to particular communicative situations and to particular styles of language. In other words, the meaning and forms of FSs are in direct relationships with each other in a given context. It should, however, be remembered that FSs tolerate some form of variation in certain situations and their restriction is, therefore, more probabilistic than absolute (Nesselhauf, 2003). Moreover, it is not an absolute rule applicable to all FSs and there are many other forms of strings which are unpredictable and can not be accounted for by grammar rules (Rott, 2009).

\subsection{Significance of FSs}

Gruber (2009) claimed that what makes formulaic language a very good and rich area for analysis is its intertextuality. He also highlights the fact that formulaic language both limits and creates options in making meaning in a particular context. FSs utilize limited set of options or underutilize the existing freedom at discourse level highly because language is governed by rules which limit the sets of choices available and only allows those options which are more permitted in its linguistic framework. Aspects of language setting clear-cut and absolute boundaries for FSs have not been specified yet. However, there are some principles for detecting and recognizing formulaic language in general.

Corrigan et al. (2009) claimed that usage-based approaches have more to contribute to FSs than generative approaches. Bannard and Lieven (2009) differentiated generative theories from the usage-based by asserting that generative theories claim that some pre-experienced innate rules are the cause of productivity in languages whereas usage-based theories consider novel utterances as the by-product of the early experiences and consequently an analogy, in terms of creating novel products, is made between what interlocutors have used before and what is produced recently. Bannard and Lieven are not the only scholars who have emphasized the critical role of experience in children's construction of language. Erman (2009) and Peters (2009) also reported that experience is a very important element in the process of learning FSs. Interestingly, aside from pragmatic functions of the FSs, they have some decorative functions in an utterance achieved through the repetition of some symmetrical compounds like here and there, last and final (Ourn \& Haiman, 2009).

\subsection{The Role of FSs in Language Acquisition}

There is general consensus on the importance of formula in the acquisition and learning of L1, L2, and FL. Some scholars such as Wray (2009) and Peters (2009) believed that learning and acquiring language starts from whole and then moves to breaking down this whole into its comprising components. They contend that learners start from mapping the biggest received pattern and then they establish their rules from what they conceive in these perceived wholes. They believe these multi word strings are learnt as a whole and there is no need for further analysis till the learner encounters such pattern frequently and seeks to find where the variation or rules lie. Bannard and Lieven (2009) added that when children face these recurrent patterns of formulaic language, they try o connect the existing construction into a complex network. This is what the researchers of this study call the "discovery process". It is a link between past and present experiences in the process of learning a language. Erman (2009) suggested that first language learners compared to their second language counterparts have more exposure to FSs. Collentine (2004) found that learners who study only at home develop discrete lexical and grammatical features while learners studying abroad create better narrative skills and are able to produce language which is more semantically dense. The use of formulaic language helps their users to manage their time efficiently. This cognitive temporal is an element which provides an opportunity to express what they intend to do while they have to think and speak at the same time (Iwasaki, 2009). Peters (1983) proposed six tasks that learners must perform in learning a language:

1. Extracting and remembering chunks from inputs they receive

2. Comparing those recently learned chunks with those which had been learnt previously 
3. Connecting them with familiar and similar chunks in various ways including pragmatic connection, semantic connection, phonological connection, and syntactic connection

4. Unpacking the chunks into some known subparts

5. Storing some of those encountered chunks in the lexicon repertoire and discarding those which may seem less useful

\section{Trying and revising them in later stages}

\subsection{Intra-individual Fixedness of FSs}

Bannard and Lieven (2009) claimed the use of FSs is different among individuals. This variation is rooted in variation in people's experiences and the rate of exposure to language. Higher degrees of exposure make FSs more frequent in interlocutors' speech. The position of strings of words in each individual's utterance depends on the context of situation and people's previous experiences. Bannard and Lieven (2009) noted that children track the regularities and rules in strings of words or sounds and then they track the frequency and later they segment these wholes into their comprising components for their later products and output productions. Their learning of multiword units depends on the rate of frequency of each individual word and even the rate of context frequency in which these multiword units are utilized for transferring one particular meaning and concept. However, it should also be noted that this process of construction happens at a slow rate and depends on connecting parts to a more complex network of constructions.

Van Lancker Sidtis (2009) distinguished between FSs and novel utterances in terms of learners' mental processing. Based on his distinction, dual process model specifies a holistic mode for the processing of FSs and an analytic mode for generating new utterances. In his research, he showed that although there is not any significant difference in recognizing FSs and novel utterances, the rate of recalling is not the same between these two. Bannard and Lieven (2009) proposed seven types of semantic slots, i.e., referent, process, attribute, location, direction, possessor, and utterance, which can be detected in various sentences. Each sentence may have a slot in which the variation can be posited. Leave the class in the sentence I want to leave the class, for example, occupies a slot which can be filled with options dealing with the process and substituted by different options. Chunks may also be analyzed through the process of analogy. Hearing strings of words, learners find some overlapping elements in both phonological and positional patterns. However, they also find some type of variations among these consistently present patterns. Therefore, they create a frame and slot construction out of which they extract some rules for their further utterances. These processes are not the same among all children and mostly depend on the amount of their exposure and previous experiences.

A wide range of FSs are not newly created, i.e., they are not produced from the interplay between grammatical regularities and mental lexicon of the interlocutors. FSs such as idioms, proverbs, and so on, however, have some features in common. They are stereotyped forms which have a conventionalized meaning (Van Lancker Sidtis, 2009), i.e., they contain specified word and appear in specified orders. Moreover, their meanings are conventionalized and they are idiosyncratic. The meanings of FSs are thus either non-literal or metaphoric. As Wray (2002) pointed out the intended meaning of these formulae is not the sum of their parts.

\subsection{FSs and Successful Communication}

Successful communication plays a critical role both in spoken discourse and written one. Ohlrogge (2009) corroborated previous arguments considering FSs as forms which break the rules and regularities of language. He also added that these abnormalities can be observed in many areas of language including grammar and lexical zones. Therefore, the learners of new language would face many challenges and problems while encountering these irregularities. Learners, on the one hand, must learn new forms and functions to apply these components in right context and on the other hand, they face multiword sequences which should be utilized in a given discourse. Yorio (1989) assumed that there may be some positive correlation between the learner's correct use of FSs and their overall language proficiency. Since employing the right FS in appropriate contexts requires enough mastery of a given language, learners may tend to use the FSs which are more frequently used and heard rather than the new and challenging ones which seem more laborious and hard to be stored in mind.

Halliday (1973), for example, argued that pragmatic forces are the primary reasons in extracting language items and producing the utterances. Children's early production of formulaic language provides a good example for Halliday's argument. Their early utterances are usually practical expressions and children usually make connections between the form they hear and the contexts in which they are produced. When they use the word strings like thank you, they know that they are using these sets of words for accomplishing appreciation.

Particular FSs are more easily retrieved from the memory than the others. Lieberman in 1963 found that predictable 
FSs are more easily remembered. This predictability sometimes emerges out of associative connection among co-occurring words. The result of co-occurrence is the production of larger units or prefabricated phrases, which are represented differently in the memory and this usually leads the users to encounter them as a whole rather than as a sum of their components (Kapatsinski \& Radicke, 2009).

\subsection{Fluency and FSs}

In speech, fluency is almost accepted as a function of variables related to time such as rate of speaking and the number of words or syllables uttered between pauses (wood, 2008). Although this definition is the most prevalent one, there are many disagreements over this explication of fluency (see Wingate, 1984). Neither have there been enough investigations on the relationship between FSs in speech and the effectiveness of oral communication. Fluency is, nonetheless, measured as syllables uttered per minute, the length of run (the number of syllables uttered between pauses), and the number of pauses (Wood, 2008). It is highly influenced by the use and control of FSs. These prefabricated units, because of their holistic nature, help interlocutors save their time and energies in an appropriate way to facilitate their later communications. The procedualized and automatized nature of formulae also helps enhance communication (Wood, 2008). In 1983, Pawley and Syder established a connection between fluent language and FSs. Speakers prefer to use predicable phrases rather than utilize and process an unlimited number of available lexical and grammatical options.

Collocations, as a prevalent type of FSs, are "a heterogeneous group of multiword expressions that can take many different forms" (Erman, 2009, p. 326). While Sinclair defined collocations as "the co-occurrence of two or more words within a short space of each other in a text" (1991, p. 170), Stubbs (2001) approached them as "the lexical relations between two or more words which have a tendency to co-occur within a few words of each other in running texts" (p. 24). Still another definition is provided by Ellis and Frey (2009) who looked at collocations as co-occurrence of particular words in a preferred way.

Regardless of the diversity of definitions offered, collocations are the most influential items in making a text readable and even an utterance more understandable. Erman (2009) noted that in addition to grammar and overall coherence, strings of words and more specifically collocations have a significant contribution in adjusting a text into normality and in feeding a text into comprehensibility. He claims that the lack of fluency in L2 writing stems from learners' lack of ability in using adequate collocations and even in their lack of proficiency in putting them in right places. Two intrinsic and extrinsic features of collocations should, therefore, be taken into account in studying them. While the former refers to the meaning of the collocations in a given context and their functions in related situations, the latter deals with the restricted choice of their elements.

Wray (2002) believed that language users take FSs holistically rather than piecing them together by employing some other components. He believed language users receive and utilize them as a whole till they reach a level where they need to create some novel utterances in their speech. In this stage, they start to analyze those holistically stored chunks and extract the required rules and regularities which fit their current production. These composite structures have unitary meanings as Erman (2009) pointed out. The correct and appropriate usage of the formulaic strings can also enhance the harmony and beauty of the discourse produced by the interlocutors.

In a qualitative study done by Shams and Shamsaee (2010), for example, it was found that utterances with higher rates of formulae seem more harmonious and interesting to addressees. Researchers also found that utterances with higher rate of formulae can be more easily retrieved from the memory for later usages. Similarly, the results obtained by Hay and Bresnan (2006) showed that formulaic sequences, or syntactic phrases as they call it, may be coded and stored in the memory along with their phonological details and consequently be retrieved as pragmatic units with less effort on the part of the speaker.

Each FS is primed in our utterances as a schema (Khodadady, Pishghadam, Fakhar, 2010; Khodadady, Shirmohammadi \& Talebi, 2011) as a result of the interplay between the interlocutors' background knowledge with the concept it represents in the interlocutors' mind and the effects of their various encounters with the schema in oral and written texts. This priming is also happening in a complex network of relations between semantic, pragmatic, and syntactic relations the FS enters within produced utterances/sentences. FSs are thus closely tied to and sensitive to contextual, cultural, and interactive routines of the society in which they are employed for communicative purposes.

\subsection{Empirical Background}

In the study done by Ohlrogge (2009), it was found that there is a strong correlation between the grade level of the students and their use of two types of FSs: idioms/collocations and personal stance markers. In terms of frequency of use, Bybee (2002) maintained that reduction in phonological rules is largely observed in words and phrases with 
higher frequency of usage than those with the lower. Similarley, Syder and Pawley (1983) found that native-like fluency is highly associated with the degree of storing and retrieving formulaic constructions from lexical repertoire of the learners.

Rott (2009) showed that the topic and genre of the writing compositions influence the number of FSs employed by learners. He also found that awareness-raising in pre-writing tasks bring about the application of more FSs in writing. Considering genres as a system having its own unique features, it might be concluded that like other systems of language it develops, regularizes, and at the same time conventionalizes its specific sequence of words and consequently their own FSs to maintain and enhance a better and more effective communication among interlocutors. In a study done by Dorgeloh and Wanner (2009), for example, it was found that in writing abstracts for journals, researchers develop their own strategy of reporting by employing some prefabs as a dominant part of their research. Similarly, it was found that language learners could produce more fluent utterances after a period of focused instruction of FSs (Wood, 2008). The use of collocations in utterances also helps them create more output in a shorter period of time. The use of collocations and other forms of FSs help learners experience less cognitive load while processing new utterances. Wood (2008) claimed that the degree of novelty in utterances is often due to the extent of the use of two-word lexical units or FSs.

\subsection{Ohlrogge's Categorization of FSs}

Ohlrogge (2009), inspired by Wray's (2002) working definition of FSs, proposed eight categories to classify them. Categories such as collocation or idioms seem to have a clear definition for Ohlrogge, but to clarify some other, he uses other scholars' definition as his reference. For example, he adopted the definition of phrasal verbs from Crystal (2003, p. 352) and his fourth category called "personal stance markers" is actually similar to Pawly and Sider's (1983) "sentence frames". And finally the category "language copied from the prompt" is a reformulation of a similar concept proposed by Kennedy (2003). Table 1 shows the categories and their examples taken from Ohlrogge's corpus.

It should be mentioned that since the nature of corpus in this study is different form that of Ohlrogge's, the label for the eighth category has been changed into "fixed biographical information." It denotes a sequence that almost all the IELTS candidates are bound to use due to the fixed questions always asked in the first section of the IELTS speaking module.

\section{Method}

\subsection{Participants}

Participants of this study were 41 female university students majoring in TEFL and Translation at International Imam Reza University, Mashhad, Iran. The age of the participants ranged from 18 to 35 . They had enrolled in a course for listening and speaking. Since homogeneity of the participants was not required in this study given the nature of hypotheses, no filtering was applied regarding the participants' level of proficiency. All the participants were informed about the general objectives of the project and the confidentiality of the personal information revealed during the sessions and their explicit consent was obtained; however, giving any type of detailed information that would influence their use of FSs was avoided by the researchers i.e. the examples of FSs or their potential pragmatic contribution to one's speaking were not revealed to the participants.

\subsection{Instruments}

The main instrument used in this study was the IELTS speaking specimen (2005) which was officially provided by the IELTS Center and adopted by the researchers to be administered in the speaking interview sessions. The second instrument used in the study was IELTS Listening specimen which included 40 items. The Alpha Chronbach Coefficient of reliability for the administration of this test in the present research was found to be 0.84 . The rating criteria for scoring the participants' performance were also provided by the same source.

\subsection{Procedure}

At the first phase of study, the participants took the IELTS Listening Test and their scores were calculated. At the second phase, each participant was individually interviewed by one of the researchers. In accordance to IELTS design, each session comprised three sections. In the first section which usually takes around 4-5 minutes, participants were asked to introduce themselves and then a number of simple questions about familiar topics were asked. In the second section, participants were given a question card and were asked to talk about it for about 2 or 3 minutes. In the third part, the examiner asked a number of further questions which were somehow related to the topic of section 2; this part took 5-6 minutes. The interview sessions were digitally recorded. The spoken corpus consisting of 450 minutes ( 7.5 hours) of the interviewees' recorded speech was then explored in search of the instance of FSs as specified in Table 1. 


\subsection{Data Analysis}

The data collected in this study was used for frequency analysis, correlation analysis and discriminant function analysis. In the frequency analysis, the number of eight types of FSs found in the spoken corpus was counted and categorized. In the correlation analyses, the relationships between the frequency of the use of FSs and the participants' listening and speaking scores were investigated. Finally, in the discriminant function analysis, the predictive value of the frequency of the use of FSs for assigning the learners into high and low groups of overall speaking and also speech fluency were analyzed. In DFA set 1, overall speaking performance (calculated as the mean of scores given for grammar, vocab, pronunciation and fluency) was taken as the grouping variable and Transitions and Personal Stance Markers were considered as the model predictors. In DFA set 2, the grouping variable was replaced by speech fluency and the model predictors remained the same. The results of these analyses are presented in the following sections.

\section{Results and Discussion}

Altogether 906 FSs were used by the participants of this study during the total time of 450 minutes of speech they produced. The percentages of the FSs used in each of Ohlrogge's (2009) framework are presented in Table 2. It should be mentioned that since no instance of "Rhetorical use of formulae" were found in the corpus, this category was omitted from the study and the frequency analysis was done on the remaining seven categories. As can be seen in Table 2, the most and least frequent types of FSs are collocations (36\%) and idioms $(0.7 \%)$ are, respectively.

Table 3 shows the descriptive statistics for the separate scores given to the participants' performance in the four aspects of speaking, i.e., grammar, lexical resource, pronunciation and fluency and also for the overall speaking and listening scores. As can be seen, the standard deviation of listening scores is about 0.4 units higher than overall speaking and speaking component scores, indicating that it could differentiate among the participants better than the other measures. Lexical resource scores and overall speaking scores have the narrowest range (3) and the listening scores are distributed across the widest range among the other scores.

\subsection{Correlation Analysis}

Table 4 presents the correlations among the speaking components and listening with the categories of FSs. Among the results, the low and insignificant relationship between the participants' use of collocations and their level of proficiency was unexpected because it is an established belief in language classrooms that the frequency of collocations used by the learners is directly associated with their proficiency. For example, in a study on the teaching of collocation, Koosha and Jafarpour (2006) concluded that "since the use of collocations was highly correlated with EFL learners' language proficiency, collocations should be considered as an important factor in determining their overall proficiency" (p. 205). And it is exactly because of this established belief that teaching such formulae usually receives more attention and is assigned a high level of priority by language teachers as opposed to other categories of FSs proposed by Ohlrogge (2009).

However, as can be seen in Table 4, there is no significant relationship between the frequency of collocations and the participants level of speaking an listening proficiency though collocations were the most frequently used FSs. One possible explanation for the lack of significant relationship between collocations and language proficiency is that frequency may not reflect the functional value of FSs alone. It must be accompanied by other measures such as appropriacy, for which there is no standard set yet, to provide a hybrid measure which can represent the pragmatic value of the use of FSs more precisely. The negative and significant relationship between overall speaking score and the frequency of fixed bio $(r=-0.31, p<.05)$ is in accordance with Kebbedy's (2003) claim that that the use of this type of formulae occurs more among less proficient learners.

Transitions and Personal Stance Markers are the only FSs which show significant relationship with participants speaking components and their overall speaking, indicating that there is pragmatic quality associated with their use of these two FSs. And it can also be stated that this quality does not become established with frequency because if that was the case, then the significant predictors must have been the most frequent categories too; however, as it can be seen in Table 2, this is not the case. Transitions and Personal Stance Markers do predict speech fluency but are less frequent than Collocations and Fixed bio.

\subsection{DFA: Overall Speaking Ability vs. Speech Fluency}

How do FSs predict the membership of each individual in low and high groups classified either as less and more fluent learners or as less and more proficient speakers? To find the answer, two sets of discriminant function analyses were run. Tables 5 and 6 present the main indexes of the result of DFA for these two sets.

The statistics of Table 5 reflect the viability of running DFA for analyzing characteristics of different groups in our data set. The non-significant Box's $M$ values ensure the validity of the comparisons made between the statistics of 
low and high groups. As it can be seen, the eigenvalue of speaking as the grouping variable is three times more than speech fluency. This means that the use of "personal stance markers" and "transitions" can predict one's membership in low or high groups of overall speaking ability three times more efficiently that they can for that of speech fluency. The results show that the correlation between discriminant scores which produced the grouping variable and the scores within the groups is 0.57 for speaking and 0.37 for speech fluency. Therefore, the predictions made based on the use of personal stance markers and transitions for the overall speaking ability are more realistic than that of speech fluency. Smaller values of Wilks' lambda indicate greater discriminatory power of the function. As it can be seen, the discriminatory power of our model predictors (Personal Stance Markers and Transitions) is more (smaller Lambda: 0.67) when predicting overall speaking ability compared with the same index for predicting speech fluency (greater Lambda: 0.87). The main discriminant function coefficients are shown in Table 6.

The structure matrix statistic shows the correlation between each variable and the discriminant function. The values for speaking predicted by the use of Personal Stance Markers have a high correlation (0.83) with real speaking scores, whereas a lower coefficient is obtained for Transitions (0.48). As Table 6 shows, the use of Personal Stance Markers can correctly assign $\% 41$ of cases to the group with low speaking ability or the use of Transitions can correctly assign $\% 52$ of cases to the group with high speech fluency. In general, one can see that the predictions made about the high groups (speaking: $0.86>0.41$; speech fluency: $0.52>0.28$ ) are more real across both types of FSs. In additions, the classification of low and high groups of speaking ability made by these FSs is more realistic than that of speech fluency.

\section{Conclusion}

This study was conducted for three purposes: 1) finding out what types of FSs are used more frequently by the Iranian language learners; 2) investigating the relationship between FSs and language proficiency; and 3) assessing the predictability of speech fluency based on the learners' use of FSs. The results of frequency analysis done on the spoken corpus show that Collocations and Fix Autobiographical Sequences are the first and second most frequent types of FS used by the learners while Idioms and Phrasal Verbs are the least and second least frequent FSs. However, the results of correlation analysis show that the use of collocations does not have a significant relationship with learners' overall proficiency, indicating that the frequency of use is not a reliable index for the pragmatic value of the FSs.

In addition to specifying the most frequent FSs, it was found that among the eight categories established by Ohlrogge (2009), Personal Stance Markers and Transitions are the only types of FS that have a significant relationship with learners' speech fluency. All the other types of FS, particularly collocations, do not reveal any type of significant relationship with the fluency of speaking. And finally, the application of two sets of DFA (Discriminant Function Analysis) showed that Personal Stance Markers and Transitions can predict overall speaking ability better than speech fluency.

The findings of this study can be used in syllabus design, language teaching and assessment. The prioritization of the learning of different types of FSs can be done based on its results and thus more informed decisions can be made while teaching FSs to the learners. Overestimating the role of frequency and ignoring the pragmatic subtleties of the use of FSs should be avoided specially in the IELTS preparation courses which heavily rely on providing the students with FSs. The criteria for the assessment of the learners' performance in using FSs can be refined to increase the construct validity of the tests developed for this purpose.

The most important implication of the findings in the present study is that the internal mental mechanisms which form and are formed by the use of FSs are meaningfully related to language skills and components. The difference observed between the predictive power of using FSs as an indicator of overall speaking ability, i.e., the mean core obtained on speech fluency as well as the knowledge of grammar, knowledge of vocabulary, pronunciation, and speech fluency reflect the necessity of the in-depth analysis of the interaction of FSs with morphology, syntax, semantics and pragmatics of any given language. The miscrostructural approach of schema theory (Khodadady, 1997) can provide researchers with a firm ground to investigate what type of words and FSs are employed by learners and explore their contextual realization in a wide range of written and spoken texts.

\section{References}

Bannard, C., \& Lieven, E. (2009). Repetition and reuse in child language learning. In R. Corrigan, E. Moravcisk, H. Ouali, \& K. Wheatley (Eds.), Formulaic language: Acquisition, loss, psychological reality, and functional explanations, Vol. 2. Philadelphia: John Benjamins Publishing Company. pp. 299-321

Bybee, J. (2002). Phonological evidence for exemplar storage of multiword sequences. SSLA, 24, 215-221

Collentine, J. (2004). The effects of learning contexts on morphosyntactic and lexical development. SSLA, 26, 
$227-248$

Corrigan, R., Moravcisk, E., Ouali, H., \& Wheatley, K. (2009). Introduction: Approaches to the study of formulae. In R. Corrigan, E. Moravcisk, H. Ouali, \& K. Wheatley (Eds.), Formulaic language: Acquisition, loss, psychological reality, and functional explanations, Vol. 2. Philadelphia: John Benjamins Publishing Company. pp. XI-XXIII

Crystal, D. (2003). A dictionary of linguistics \& phonetics (5th ed.). New York: Wiley-Blackwell.

Doregeloh, H., \& Wanner, A. (2009). Formulaic argumentation in scientific discourse. In R. Corrigan, E. Moravcisk, H. Ouali, \& K. Wheatley (Eds.), Formulaic language: Acquisition, loss, psychological reality, and functional explanations, Vol. 2. Philadelphia: John Benjamins Publishing Company. pp. 524-544

Ellis, N. C., \& Frey. E. (2009). The psychological reality of collocations and semantic prosody: Affective priming. In R. Corrigan, E., Moravcisk, H. Ouali, \& K. Wheatley (Eds.), Formulaic language: Acquisition, loss, psychological reality, and functional explanations, Vol. 2. Philadelphia: John Benjamins Publishing Company. pp. 474-496

Erman, B. (2009). Formulaic language from a learner perspective: What the learner needs to know. In R. Corrigan, E. Moravcisk, H. Ouali, \& K. Wheatley (Eds.), Formulaic language: Acquisition, loss, psychological reality, and functional explanations, Vol. 2. Philadelphia: John Benjamins Publishing Company. pp. 324-346

Gruber, M. C. (2009). Accepting responsibility at defendants' sentencing hearings. In R. Corrigan, E. Moravcisk, H. Ouali, \& K. Wheatley (Eds.), Formulaic language: Acquisition, loss, psychological reality, and functional explanations, Vol. 2. Philadelphia: John Benjamins Publishing Company. pp. 545-566

Haiman, J., \& Ourn, N. (2009). Decorative symmetry in ritual (and everyday) language. In R. Corrigan, E. Moravcisk, H. Ouali, \& K. Wheatley (Eds.), Formulaic language: Acquisition, loss, psychological reality, and functional explanations, Vol. 2. Philadelphia: John Benjamins Publishing Company. pp. 567-587

Halliday, M. (1973). Explorations in the functions of language. London: Edward Arnold.

Hay, J., \& Bresnan, J. (2006). Spoken syntax: The phonetics of giving a hand in New Zeland English. The Linguistic Review, 23, 321-349. http://dx.doi.org/10.1515/TLR.2006.013

Iwasaki, S. (2009). Time management formulaic expression in England and Thai. In R. Corrigan, E. Moravcisk, H. Ouali, \& K. Wheatley (Eds.), Formulaic language: Acquisition, loss, psychological reality, and functional explanations, Vol. 2. Philadelphia: John Benjamins Publishing Company. pp. 589-614

Kapatsinski, V., \& Radicke, J. (2009). Frequency and the emergence of prefabs. In R. Corrigan, E. Moravcisk, H. Ouali, \& K. Wheatley (Eds.), Formulaic language: Acquisition, loss, psychological reality, and functional explanations, Vol. 2. Philadelphia: John Benjamins Publishing Company. pp. 500-520

Kennedy, G. (2003). Structure and meaning in English. Harlow: Longman/Pearson.

Khodadady, E., Pishghadam, R., \& Fakhar, M. (2010). The relationship among reading comprehension ability, grammar and vocabulary knowledge: An experimental and schema-based approach. Iranian EFL Journal, 6(2), 7-49

Khodadady, E., Shirmohammadi, S., \& Talebi, F. (2011). Brainstorming and its effect on critical thinking and speaking skills. Iranian EFL Journal, 7(1), 51-66

Kjellmer, G. (1987). Aspects of English collocations. In W. Meijs (Ed.), Corpus linguistics and beyond. Amsterdam: Rodopi. pp. 133-140

Koosha, M., \& Jafarpour, A. (2006). Data-driven learning and teaching collocation of prepositions: The case of Iranian EFL adult learners. Asian EFL Journal, 8(4), 192-209

Lieberman, P. (1963). Some effects of semantic and grammatical context on the production and perception of speech. Language and speech, 16, 172-187

Nesselhauf, N. (2003). The use of collocations by advanced learners of English and some implications for teaching. Applied Linguistics, 53, 223-242. http://dx.doi.org/10.1093/applin/24.2.223

Ohlrogge, A. (2009). Formulaic expression in intermediate EFL writing assessment. In R. Corrigan, E. Moravcisk, H. Ouali, \& K. Wheatley (Eds.), Formulaic language: Acquisition, loss, psychological reality, and functional explanations, Vol. 2. Philadelphia: John Benjamins Publishing Company. pp. 375-386

Pawley, A., \& Syder, F. H. (1983). Two puzzles for linguistic theory: Nativelike selection and nativelike fluency. In J. C. Richards, \& R. W. Schmidt (Eds.), Language and communication. New York: Longman. pp. 191-226 
Peters, A. (1983). The units of language acquisition. Cambridge: Cambridge University Press.

Peters, A. M. (2009). Connecting the dots to unpack the language. In R. Corrigan, E. Moravcisk, H. Ouali, \& K. Wheatley (Eds.), Formulaic language: Acquisition, loss, psychological reality, and functional explanations, Vol. 2. Philadelphia: John Benjamins Publishing Company. pp. 387-402

Sinclair, J. (1991). Corpus, concordance, collocation. Oxford: Oxford University Press.

Stubbs, M. (2001). Words and phrases: Corpus studies of lexical semantics. London: Blackwell Publication.

Van Lancker Sidtis, D. (2009). Formulaic and novel language as a "dual process" model of language competence: Evidence from surveys, speech samples, and schemata. In R. Corrigan, E. A. Moravcsik, H. Ouali, \& K. M. Wheatley (Eds.), Formulaic language: Acquisition, loss, psychological reality, function, Vol. 2, Typological studies in language. Amsterdam: John Benjamins. pp. 445-472

Wingate, M. E. (1984). Fluency, disfluency, dysfluency, and stuttering. Journal of Fluency Disorders, 17, 163-168. http://dx.doi.org/10.1016/0094-730X(84)90033-0

Wood, D. (2009). Effects of focused instruction of formulaic sequences on fluent expression in second language narratives: A case study. ACLA, 1(12), 39-57

Wray, A. (2002). Formulaic language and the lexicon. Cambridge: Cambridge University Press. http://dx.doi.org/10.1017/CBO9780511519772

Yorio, C. (1989). The other side of the looking glass. Journal of Basic Writing, 8(1), 32-45

Zahedi, K., \& Shams, M. (2011). Exploring the Iranian candidates' use of formulaic sequences in the writing module of IELTS. Iranian EFL Journal, 7(2), 21-41

Table 1. Ohlrogge's (2009) Categorization of FSs

\begin{tabular}{|l|l|l|}
\hline & Categories & Examples \\
\hline 1 & Collocations & High hopes, heavy fines \\
\hline 2 & Idioms & Money doesn't grow on trees; to cut a long story short \\
\hline 3 & Phrasal verbs & Grow up; go out with \\
\hline 4 & Personal stance markers & In my opinion; without a doubt \\
\hline 5 & Transitions & First of all; in conclusion \\
\hline 6 & Language copied from the prompt & - \\
\hline 7 & Generic rhetoric & It should come at no surprise that... \\
\hline 8 & Irrelevant biographical information & My name is Maria and I am sixteen years old. \\
\hline
\end{tabular}

Table 2. Percentages of the Use of FS Categories

\begin{tabular}{|l|c|c|c|c|c|c|c|}
\hline & Idioms & Collocations & $\begin{array}{c}\text { Phrasal } \\
\text { Verbs }\end{array}$ & $\begin{array}{c}\text { Personal Stance } \\
\text { Markers }\end{array}$ & Transitions & $\begin{array}{c}\text { Copied } \\
\text { Speech }\end{array}$ & $\begin{array}{c}\text { Fixed } \\
\text { Bio. }\end{array}$ \\
\hline Frequency & 6 & 330 & 14 & 179 & 139 & 52 & 189 \\
\hline Percentage & 0.7 & 36 & 1.5 & 20 & 15 & 6 & 20.8 \\
\hline
\end{tabular}


Table 3. Descriptive Statistics for the Speaking and Listening Tests

\begin{tabular}{|l|c|c|c|c|c|c|}
\hline & $\mathrm{N}$ & Mean & $\begin{array}{c}\text { Std. } \\
\text { Deviation }\end{array}$ & Std. Error Mean & Minimum & Maximum \\
\hline Sp. (Grammar) & 41 & 5.62 & 0.98 & 0.15 & 4.0 & 7.5 \\
\hline Sp. (Lexical Resource) & 41 & 5.51 & 0.96 & 0.15 & 4.0 & 7.0 \\
\hline Sp. (Pronunciation) & 41 & 5.95 & 0.99 & 0.15 & 4.0 & 7.5 \\
\hline Sp. (Fluency) & 41 & 5.45 & 0.99 & 0.15 & 3.5 & 7.0 \\
\hline Speaking & 41 & 5.87 & 0.91 & 0.16 & 4.0 & 7.0 \\
\hline Listening & 41 & 3.89 & 1.34 & 0.21 & 0.0 & 5.5 \\
\hline
\end{tabular}

Table 4. Correlations between the Frequency of the Use of FS Categories \& Speaking and Listening Skills

\begin{tabular}{|c|c|c|c|c|c|c|c|c|}
\hline & 氞 & 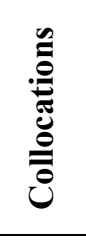 & 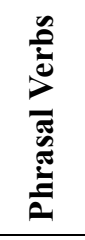 & 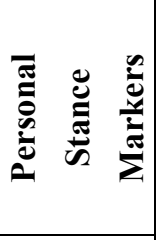 & 竘 & 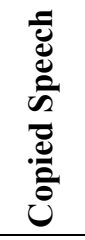 & 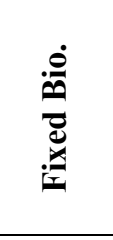 & $\stackrel{\frac{\pi}{0}}{\theta}$ \\
\hline Sp. (Grammar) & 0.11 & 0.11 & -.01 & $0.57 * *$ & $0.50 * *$ & 0.12 & -0.12 & $0.40^{*}$ \\
\hline $\begin{array}{ll}\text { Sp. } & \text { (Lexical } \\
\text { resource) } & \end{array}$ & 0.12 & 0.03 & 0.02 & $0.41 * *$ & $0.48 * *$ & 0.27 & -0.08 & $0.34 *$ \\
\hline Sp. (Pronunciation) & 0.20 & 0.17 & 0.11 & $0.61 * *$ & $0.43 * *$ & 0.14 & -0.11 & $0.47 * *$ \\
\hline Sp. (Fluency) & 0.13 & 0.06 & 0.11 & $0.39 * *$ & $0.42 * *$ & 0.06 & -0.24 & 0.28 \\
\hline Speaking & 0.18 & 0.03 & 0.05 & $0.50 * *$ & $0.32 *$ & 0.04 & $-0.31 *$ & 0.25 \\
\hline Listening & 0.19 & 0.13 & 0.09 & 0.29 & 0.28 & 0.02 & -0.11 & 0.27 \\
\hline
\end{tabular}

* significance at 0.05 level;

** significance at 0.01 level

Table 5. The Results of DFA for Set 1 (Grouped by Speaking) and Set 2 (Grouped by Speech Fluency)

\begin{tabular}{|c|c|c|c|c|c|c|c|c|}
\hline \multirow{2}{*}{$\begin{array}{c}\text { Model Predictors: } \\
\text { Personal Stance } \\
\text { Markers } \\
\& \\
\text { Transitions }\end{array}$} & \multicolumn{2}{|c|}{ Eigenvalues } & \multicolumn{3}{|c|}{$\begin{array}{c}\text { Box's Test of } \\
\text { Equality of } \\
\text { Covariance } \\
\text { Matrices }\end{array}$} & \multicolumn{3}{|c|}{ Wilks' Lambda } \\
\hline & $\begin{array}{c}\text { Eigenv } \\
\text { alue }\end{array}$ & $\begin{array}{l}\text { Canonical } \\
\text { Correlation }\end{array}$ & $\begin{array}{c}\text { Box's } \\
\text { M }\end{array}$ & $\mathrm{F}$ & Sig. & $\begin{array}{l}\text { Wilks' } \\
\text { Lambda }\end{array}$ & $\begin{array}{l}\text { Chi- } \\
\text { Square }\end{array}$ & Sig. \\
\hline Speaking & 0.49 & 0.57 & 3.67 & 1.15 & 0.32 & 0.67 & 15.12 & 0.00 \\
\hline Speech Fluency & 0.16 & 0.37 & 4.95 & 1.55 & 0.19 & 0.86 & 5.72 & 0.05 \\
\hline
\end{tabular}


Table 6. Discriminant Function Coefficients for Transitions and Personal Stance Markers as Classifiers of Speaking and Speech Fluency

\begin{tabular}{|c|c|c|c|c|c|c|c|c|}
\hline & \multicolumn{4}{|c|}{ Speaking } & \multicolumn{4}{|c|}{ Speech Fluency } \\
\hline & \multirow{2}{*}{$\begin{array}{c}\text { Standardized } \\
\text { Canonical } \\
\text { DF } \\
\text { Coefficients }\end{array}$} & \multirow[t]{2}{*}{$\begin{array}{c}\text { Structure } \\
\text { Matrix }\end{array}$} & \multicolumn{2}{|c|}{$\begin{array}{l}\text { Classification } \\
\text { Function } \\
\text { Coefficients }\end{array}$} & \multirow{2}{*}{$\begin{array}{c}\text { Standardized } \\
\text { Canonical } \\
\text { DF } \\
\text { Coefficients }\end{array}$} & \multirow[t]{2}{*}{$\begin{array}{c}\text { Structure } \\
\text { Matrix }\end{array}$} & \multicolumn{2}{|c|}{$\begin{array}{c}\text { Classification } \\
\text { Function } \\
\text { Coefficients }\end{array}$} \\
\hline & & & Low & High & & & Low & High \\
\hline $\begin{array}{l}\text { Personal } \\
\text { Stance } \\
\text { Markers }\end{array}$ & 0.88 & 0.83 & 0.41 & 0.86 & 0.44 & 0.46 & 0.40 & 0.52 \\
\hline Transitions & 0.56 & 0.48 & 0.31 & 0.57 & 0.87 & 0.89 & 0.28 & 0.52 \\
\hline
\end{tabular}

